\title{
Alpha Tocopherol Measurement
}

National Cancer Institute

\section{Source}

National Cancer Institute. Alpha Tocopherol Measurement. NCI Thesaurus. Code C103349.

The determination of the amount of the alpha tocopherol in a sample. 